Kenneth Einar Himma

\title{
The Information Gap, the Digital Divide, and the Obligations of Affluent Nations $^{1}$
}

\begin{abstract}
:
In this essay, I would like to do three things. First, I would like to provide a broad and brief overview of the effects of absolute poverty in creating an information gap and a digital divide and the effects of these gaps in perpetuating absolute poverty. Second, I would like to show that ordinary case intuitions, normative ethical theories, and theological considerations converge in entailing a moral obligation to help those in poverty. Third, I would like to argue, all too briefly, that although this surely involves making donations of both cash and food - free of the sorts of conditions that are frequently imposed by organizations like the IMF and World Bank - it also involves donations of a sort that are specifically targeted to close the information and digital divides.
\end{abstract}

\section{Agenda}

The Bi-Directional Relationship between Absolute Poverty and the Digital and Information Divides ..............65

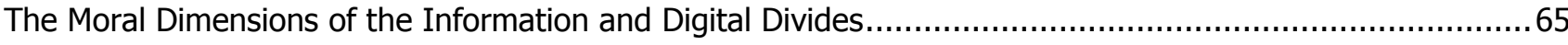

Do Affluent Nations Have a Moral Obligation to Help Developing Nations Overcome Poverty and the Information and Digital Divides?

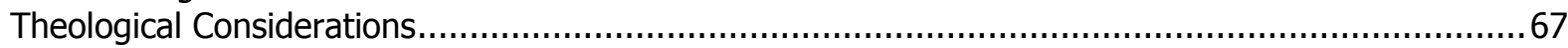

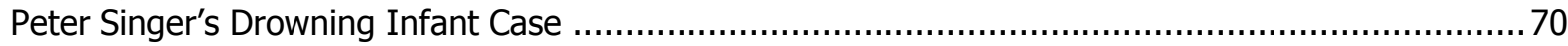

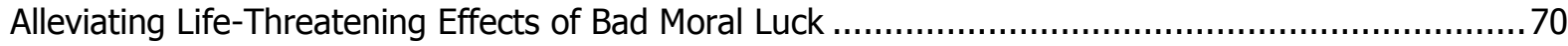

Consequentialism and Deontological Moral Theories ............................................................... 71

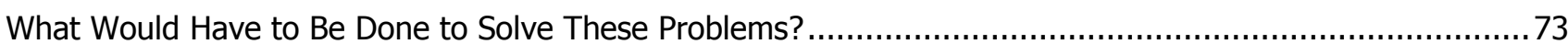

Author:

Kenneth Einar Himma:

- Department of Philosophy, Seattle Pacific University, Seattle, USA

- $\triangle$ Himma@spu.edu

\footnotetext{
${ }^{1}$ I am extremely grateful to Johannes Britz who is responsible, more than any other person for educating me on this important issue and suggesting very helpful criticism and suggestions. This paper would be much poorer but for his patience and generosity with me. I am deeply indebted to him as a friend, colleague and mentor - and a great admirer of his work, both practical and philosophical, on such matters.
} 
The global distribution of material resources should bother any conscientious person. One billion of the world's six billion people live on less than $\$ 1$ per day, while 2 billion live on less than $\$ 3$ per day. Poverty in the affluent world is largely relative in the sense that someone who is "poor" simply means he has significantly less than what others around him have. But since wealth is, unfortunately, frequently associated in the West with moral worth, it is important to realize that relative poverty is a genuinely painful condition. People who live in conditions of relative poverty are generally treated with less respect - and hence are denied something that is essential to human well-being. ${ }^{1}$

In the developing world, poverty and the suffering it causes is considerably worse. Here poverty is characteristically "absolute" in the sense that people do not have enough to consistently meet their basic needs. People in absolutel poverty lack consistent access to adequate nutrition, clean water, and health care, as well as face death from a variety of diseases that are easily cured in affluent nations. Indeed, 15 million children die every year of malnutrition in a world where the food that is disposed of as garbage by affluent persons is enough to save most, if not all, of these lives.

Fortunately, life-threatening poverty has begun to attract the attention of parties and organizations that hold passionately conflicting views on many other pressing moral issues. Liberals and conservatives in the U.S. might disagree about, say, abortion

${ }^{1}$ Nevertheless, poverty is becoming more serious in countries like the U.S., where a recent study shows an increase in the percentage of the population in "severe poverty," shich is defined as having an income less than half of that defined by the federal poverty line. The number of people living in severe poverty increased by $26 \%$ from 2000 to 2005. See, e.g., Tony Pugh, "More Americans Falling Deeper into Depths of Poverty," Seattle Times, February 26, 2007; available at http://archives.seattletimes.nwsource.com/cgibin/texis.cgi/web/vortex/display?slug=poverty26\& date $=20070226 \&$ query $=$ poverty. Moreover, there is some absolute poverty in the U.S., as there are now more than 750,000 persons who are homeless. See Stephen Olemacher, "Official Count: 754,000 people believed homeless in U.S., Seattle Times, Wednesday, February 28, 2007; available at

http://seattletimes.nwsource.com/html/nationworl d/2003592874 homeless28.html. rights; but everyone seems to agree that something should be done about absolute poverty.

It is hard to overstate the significance of this emerging consensus on absolute poverty. People in the U.S. commonly believe the only moral obligations that we owe to other people are negative in the sense they require only that we refrain from performing certain acts; for example, we are obligated not to shoot other people, but not to do something to save someone's life. That citizens in the U.S. are converging on a desire to help the absolutely poor given this unfortunate view of moral obligations is quite remarkable.

In this essay, I would like to do three things. First, I would like to provide a broad and brief overview of the effects of absolute poverty in creating an information gap and a digital divide and the effects of these gaps in perpetuating absolute poverty. Second, I would like to show that ordinary case intuitions, normative ethical theories, and theological considerations converge in entailing a moral obligation to help those in poverty. Third, I would like to argue, all too briefly, that although this surely involves making donations of both cash and food free of the sorts of conditions that are frequently imposed by organizations like the IMF and World Bank - it also involves donations of a sort that are specifically targeted to close the information and digital divides.

The argument for this latter conclusion will be grounded in two considerations. First, it will be grounded in certain basic principles that have governed "globalization" - the process by which trade barriers between countries have systematically been reduced over the last couple of decades - usually to the advantage of affluent nations and to the disadvantage of developing nations. Second, it will be grounded in certain claims about the most efficacious way to satisfy our collective and individual obligations to alleviate the conditions of lifethreatening poverty. I will conclude that (1) these measures should be borne both individually and collectively by taxpayers in affluent nations; and (2) corporations should waive certain intellectual property rights that up to now they have been extremely reluctant to waive in order to prepare developing nations for a global economy that satisfies basic principles of fairness. 


\section{The Bi-Directional Relationship between Absolute Poverty and the Digital and Information Divides}

There are gaps in access to information and information communication technologies (ICTs) within nations and between nations. Within the US, for example, there are such gaps between rich and poor citizens, whites and blacks, and urban dwellers and rural dwellers. According to the Department of Commerce (1999):

The 1998 data reveal significant disparities, including the following: Urban households with incomes of \$75,000 and higher are more than twenty times more likely to have access to the Internet than rural households at the lowest income levels, and more than nine times as likely to have a computer at home. Whites are more likely to have access to the Internet from home than Blacks or Hispanics have from any location. Black and Hispanic households are approximately one-third as likely to have home Internet access as households of Asian/Pacific Islander descent, and roughly two-fifths as likely as White households. Regardless of income level, Americans living in rural areas are lagging behind in Internet access. Indeed, at the lowest income levels, those in urban areas are more than twice as likely to have Internet access than those earning the same income in rural areas.

Other things being equal, poor people in the US are less likely to have access to online information and the ICTs that makes access possible than affluent people.

Similar gaps exist between the affluent developed world and the impoverished developing world. Although Internet access is increasing across the world, it is still the case that a comparatively small percentage of the developing world's poor has Internet access. A 2005 UNESCO report indicated that only $11 \%$ of the world's population has access to the Internet, but $90 \%$ of these persons live in the affluent industrialized developed world. ${ }^{2}$

2 Matias Ponce, "UNESCO Report Highlights Digital Divide," (November 4, 2005); available at http://english.ohmynews.com/articleview/article v iew.asp?article class=4\&no=256818\&rel no $=1$. Accessed February 16, 2007.
Although these differences in access to ICTs and information correlate with differences in wealth, there is a causal relation between them. Obviously, people who are too poor to fully meet their immediate survival needs cannot afford either ICT access and the training that prepares one to take advantage of such access. But not being able to afford such training and access is likely to perpetuate poverty in a global economy increasingly requiring the ability to access, process, and evaluate information. Lack of access owing to poverty is a vicious circle that helps to ensure continuing poverty.

\section{The Moral Dimensions of the Information and Digital Divides}

As there is confusion and disagreement about the concepts of digital and information divides, I would like to provide a brief explanation of these notions as used in this paper. A digital divide between groups $A$ and $B$ refers to a gap in meaningful access to ICTs, which requires the ability to use ICTs to economic and cultural advantage. On this conception, someone who has the relevant ICTs but can do no more with them than download music from online sharing sites has access, but not meaningful access, to ICTs because she does not have the ability, opportunity, or disposition to use them in a way that promotes her cultural knowledge or economic well-being.

An information gap between groups A and B refers not only to a gap in access to information that can potentially improve a member's cultural knowledge and economic well-being, but also refers to a lack of ability, opportunity, or disposition to use that information in a way that contributes to that member's cultural knowledge and economic well-being. Someone who can find information that can ground economically productive activity, but lacks the ability (perhaps because of underdeveloped analytic skills) or opportunity to put it to use would suffer from an information gap relative to someone who is succeeding in the "information" or "knowledge" society.

These kinds of divides are typically characterized as problems to be remedied, but the ethical issues are more complex than is commonly assumed. Someone who thinks that such gaps unambiguously present a moral wrong that must be rectified focus primarily on the benefits of ICTs and their meaningful use. Having meaningful access to ICT, which includes the skills to be able to process information in a way that creates marketable value, results in 
benefits that are economic and non-economic in character. Clearly, there are a host of marketable things someone competent with ICTs can do to improve her standard of living and well-being. Likewise, if we think that there are many things about that world that are worth knowing for their intrinsic value (as opposed to their value in bringing about some other means, such as an increase in wealth), then meaningful access to and use of ICTs can increase a person's understanding of the world - something that seems sufficiently valuable, along with the economic benefits, to characterize lack of such access to ICTs as a problem needing solution.

Of course, the moral calculus is never so simple as it may initially appear. The worldwide availability of mass media featuring content from all over the world can have the effect of reducing cultural diversity. Human culture can be thought of as analogous to artistic product - though it is collective in a way that, say, paintings are not. Human beings manufacture the cultural norms and conditions in which they live by converging upon shared assumptions about what is and is not valuable, by expressing shared tastes in the development of indigenous art, fashion, language, knowledge, and food. Exposure, say, of African nations to certain cultural content from the West can certainly expand an African's sense of the cultural possibilities and result in new cultural forms that are hybrids of African and Western influences - and this can certainly be seen as good from a moral vantage point.

However, the availability of a particular culture's content can also have the effect of eliminating cultural forms that, as a moral matter, should be preserved. Many persons, I think, share the intuition that the progressive Americanization of cultures ranging from Western European to African and Asian (in the form, for example, of a proliferation of American corporate franchises, like McDonald's, Starbucks, the Gap, in an increasing number of international cities) raises moral issues.

Moreover, resolving the divide between North and South threatens the multilingualism endemic to, for example, nations in Africa. More than $75 \%$ of the World Wide Web's content is in English - a percentage that will continue to increase as more persons in the developing world gain meaningful access to the World Wide Web - yet English is the native language for less than $50 \%$ of people with Internet access (including, of course, people in Western European nations) The proliferation of ICTs and the requisite skills to use them requires fluency in English and threatens, according to some estimates, as many as 6,000 languages currently being spoken, the majority of which are in Africa. ${ }^{3}$

But it is as important to avoid a cultural paternalism that leads to steps that insulate existing indigenous cultures from outside influences as it is to avoid the sort of cultural imperialization of which the U.S. is often accused - especially in cultures in which lifethreatening poverty is endemic.

There are no easy choices here with respect to the kind of gaps with which we are concerned. If it is important to preserve distinct cultures for the same reason it is important to preserve works of art, it is also important to protect the autonomy rights of individuals to choose the cultural forms that best express their developing sense of values and priorities. It is equally important, on this assumption, to protect the right of people subject to conditions of absolute - or, for that matter, relative - poverty to improve their standard of living so as to ensure a healthier, happier life in which they can flourish in all the ways it is reasonable to think people should flourish.

Given that total globalization of economic activity appears inevitable, I think it is fair to assume that, while the value of preserving culture is an important moral value, the values associated with making possible a more economically affluent life for the one billion people who live on less than $\$ 1.00$ a day and the two billion who live on less than $\$ 2.00$ a day outweigh the admittedly important moral value of preserving diversity. Life is more valuable than art and culture - though art and culture are obviously an important part of what makes life worth living.

This should not be taken to deny that every possible step should be taken to preserve cultural diversity and multilingualism as the affluent world attempts to solve the problems associated with the various divides (ICT, knowledge, information, skills). If diversity can be preserved while raising standards of living among the most wretched poor of the world, then it should be done. The cultural richness made possible by the world's diverse customs and languages is, from any evaluative standpoint (aesthetic, prudential, and moral), of tremendous importance and should be protected by every feasible means.

The point is rather that the moral value associated with alleviating the conditions of poverty that

\footnotetext{
${ }^{3}$ See Ponce (2005), above.
} 
threaten life, health, security and human dignity outweigh the value of such diversity if they come into irresolvable conflict. If the cost of feeding chronically malnourished individuals and making possible a certain level of affluent self-sufficiency among the world's poorest people means the disappearance of certain cultures, so much the worse for those cultures - though we should not lose sight of the fact that something of genuine moral importance is being lost. Of course, it should be emphasized that no claim is being made here that these two values cannot both be protected and secured; the claim is rather that alleviating a poverty that is beyond what most people who have never seen it can imagine outweighs preserving the diversity that enriches even the lives of people who never travel beyond the confines of the nearest large metropolitan area.

This is not, of course, an entirely comfortable position to take, but reflection on one's own preferences seems to require it. One should always be aware that intuitions and preferences are culturally conditioned, so there is a danger that my intuitions are not universally shared; if so, that is a gap in my argument. But I will take a full belly and a materially comfortable life over adherence to any particular cultural form - including the one with which I am most comfortable. It is true, of course, that Western intuitions are conditioned by the West's atomistic conception of the individual as supreme, whereas other Eastern cultures conceive of the group to which one belongs as supreme. Still, it is hard to imagine any practically rational being preferring the chronic discomfort of serious poverty to membership to any group that does not have a religious character.

\section{Do Affluent Nations Have a Moral Obligation to Help Developing Nations Overcome Poverty and the Information and Digital Divides?}

To say that $X$ is good is to not to say that $X$ is obligatory. Failure to do something morally good is not necessarily morally wrong and does not necessarily merit blame, censure, or punishment. It would be good if I were to run into a burning building to try to rescue someone, but it is not morally wrong for me to refrain from doing so; risking my life to save another is supererogatory - that is to say, morally good but beyond the call of obligation. Failure to do something morally obligatory, in contrast, is necessarily morally wrong and merits blame, censure, or punishment. We praise supererogatory acts, but not obligatory acts. We blame nonperformance of obligatory acts, but not nonperformance of supererogatory acts.

It is uncontroversial that it is morally good for affluent persons or nations to help impoverished persons or nations, but there is considerable disagreement about whether affluent persons and nations are morally obligated to help alleviate the effects of absolute poverty. As noted above, many persons in the U.S. take the position that the only moral obligations we have are negative in the sense that they require us only to abstain from certain acts; we are obligated, for example, to refrain from killing, stealing, lying, etc. On this view, we have no moral obligations that are positive in the sense that they require some positive affirmative act of some kind. It follows, on this view, that we have no moral obligation to help the poor; helping the poor is good, but beyond the demands of obligation.

Indeed, some would argue that it is a conceptual truth (derived from the content of the concept, as opposed to being derived from substantive moral norms) that helping the poor is good but not morally obligatory. On this line of analysis, helping the poor is, as a conceptual matter, "charity." But it is a conceptual truth that charity is morally good, but not obligatory; that is to say, it is a deeper implication of the very meaning of "charity" that it is supererogatory. Accordingly, charity is praiseworthy, but failure to be charitable is not blameworthy.

I think this view is both mistaken and pernicious. In the next four subsections, I will argue that this view is inconsistent with the ethics of every classically theistic religion, ordinary intuitions about certain cases, and each of the two main approaches to normative ethical theory, consequentialism and deontological ethical theory. Taken together, these arguments provide a compelling case for thinking the affluent are morally obligated to help alleviate the conditions of absolute poverty wherever they are found.

\section{Theological Considerations}

To begin, it is clear that Christian ethics entail a robust moral obligation to help the poor. Jim Wallis points out, for example, that there are 3000 refer- 
ences in the Bible to alleviating poverty. ${ }^{4}$ Jesus frequently speaks of helping the poor as a constituent of authentic religious faith in God; Matthew 25:31-46 states:

When the Son of Man comes in his glory, and all the angels with him, then he will sit on the throne of his glory. All the nations will be gathered before him, and he will separate people one from another as a shepherd separates the sheep from the goats, and he will put the sheep at his right hand and the goats at the left. Then the king will say to those at his right hand, "Come, you that are blessed by my Father, inherit the kingdom prepared for you from the foundation of the world; for I was hungry and you gave me food, I was thirsty and you gave me something to drink, I was a stranger and you welcomed me, I was naked and you gave me clothing, I was sick and you took care of me, I was in prison and you visited me." Then the righteous will answer him, "Lord, when was it that we saw you hungry and gave you food, or thirsty and gave you something to drink? And when was it that we saw you a stranger and welcomed you, or naked and gave you clothing? And when was it that we saw you sick or in prison and visited you?" And the king will answer them, "Truly I tell you, just as you did it to one of the least of these who are members of my family, you did it to me." Then he will say to those at his left hand, "You that are accursed, depart from me into the eternal fire prepared for the devil and his angels; for I was hungry and you gave me no food, I was thirsty and you gave me nothing to drink, I was a stranger and you did not welcome me, naked and you did not give me clothing, sick and in prison and you did not visit me." Then they also will answer, "Lord, when was it that we saw you hungry or thirsty or a stranger or naked or sick or in prison, and did not take care of you?" Then he will answer them, "Truly I tell you, just as you did not do it to one of the least of these, you did not do it to me." And these will go away into eternal punishment, but the righteous into eternal life.

The implicit conception of authentic faith here is that it is not just about believing certain propositions; it is also about doing things - and one of those things is to help the poor. Not helping others in need is tantamount to rejecting Jesus. Since (1)

4 Erin Curry, "Jim Wallis, Dems' Favorite Evangelical?" Baptist Press (January 19, 2005); available at

http://www.bpnews.net/bpnews.asp?ID=19941. Accessed February 17, 2007. this is justifiably punished and (2) punishment is justified only for failures to do what is obligatory, it follows that helping others is morally obligatory.

If more is needed, Matthew 22:34-40 describes the foundational principles of Christian ethics as follows:

When the Pharisees heard that he had silenced the Sadducees, they gathered together, and one of them, a lawyer, asked him a question to test him. 'Teacher, which commandment in the law is the greatest?' He said to him, ' "You shall love the Lord your God with all your heart, and with all your soul, and with all your mind." This is the greatest and first commandment. And a second is like it: "You shall love your neighbour as yourself." On these two commandments hang all the law and the prophets.'

In these verses, Jesus informs his questioner we are "commanded" - and hence obligated - to love our neighbors as ourselves. But "love" cannot refer to the emotions or feelings we ordinarily use the term "love" to pick out. First, what we feel is beyond our direct volitional control and we cannot be obligated to do what we is beyond our direct volitional control; as the matter is usually put, "ought implies can." Since I cannot efficaciously will that I feel towards some stranger the joyous emotion that I feel, for example, towards my wife or towards my nieces, I cannot be obligated to do so. Second, we do not experience that feeling towards ourselves; while we are self-interested and regard ourselves with esteem, this is different from the kind of emotion we feel towards other people we love. The day I look in the mirror and feel in response what I feel when I see my nieces is a day I will immediately seek some therapy for what is clearly a pathological narcissism.

Although many theologians have interpreted "neighbors" as applying only to Christians, this is implausible. ${ }^{5}$ The New Testament is clear about the passages in which it refers to all people. Christians are typically referred to as "brethren" or as comprising the "body of Christ" (or the Church). Neighbors, properly construed in conjunction with the other verses in which Jesus insists upon helping the poor is best construed as referring to all people - Christians and non-Chrisians alike. Indeed, the Pauline letters are famous for the egalitarian view of salvation that is promoted; there is no "chosen people"

${ }^{5}$ I'm indebted to Johannes Britz for this insightful concern. 
as the Old Testament seems to assert; we are all children of God with the possibility of salvation.

The obligation to love our neighbors as ourselves is properly construed as an obligation to treat the interests of other people as important as our own and this clearly entails that the affluent are obligated to help the poor. Someone who spends money on unnecessary fashionable clothing is not treating the interests of someone in conditions of life-threatening poverty as being as important as her own because basic needs clearly outweigh desires for life's luxuries. It is clear that this first principle of Christian ethics requires the affluent to deploy some of their disposable income to help alleviate absolute poverty.

Judaism grounds Tzedakah, an obligation to help the poor, in both the Torah and the Talmud. At the outset, it is important to note that Leviticus 19:18 states the very law that entails an obligation to help the poor in Christianity: "You shall not take vengeance or bear a grudge against any of your people, but you shall love your neighbour as yourself: I am the Lord." The same interpretive considerations applied to the New Testament statement are relevant here, as Jesus regarded himself as a teacher of the Jewish tradition and was regarded by followers as the fulfillment of Jewish prophecy.

Other verses are more specific. Leviticus 23:22 puts the point in terms of agricultural products, but the point remains the same: "And when you reap the harvest of your land, you shall not reap all the way to the edges of your field, or gather the gleanings of your harvest; you shall leave them for the poor and the stranger." Similarly, Deuteronomy 14:28-29 explicitly requires tithing: "Every third year, you shall bring out a full tithe of your yield of that year, but leave it within your settlements. Then ... the stranger, the fatherless, and the widow in your settlements shall come and eat their fill."

The Talmud is no less specific. Tractate Baba Bathra states: "It has been taught: R. Meir used to say: The critic [of Judaism] may bring against you the argument, 'If your God loves the poor, why does he not support them?' If so, answer him, 'So that through them we may be saved from the punishment of Gehinnom.'" As Rabbi Maurice Lamm sums up the Jewish view: "Support for the disadvantaged in Judaism is not altruism. It is "justice." 6 And to do

6 Rabbi Maurice Lamm, "Support for the disadvantaged in Judaism is not altruism -- it is nothing justice, of course, is obligatory; in the case of Judaism, it is necessary to save the Jew from a "meaningless death." As such, it is a commandment and an obligation.

Finally, Islam regards the obligation to help the poor (Zakat) as one of the five basic obligations (or "pillars," as these obligations are commonly called) of its faith. These pillars obligate Muslims (1) to declare that there is no God but Allah and Muhammad is the Messenger of God (Shahada); (2) to worship in prayer five times daily while facing Mecca (Salat); (3) to fast from sunrise to sunset during the holy month of Ramadan (Sawm); (4) to make a pilgrimage to Mecca (Hajj); and (5) to give to the poor and needy (Zakat). ${ }^{7}$ Once a tax collected by the government, satisfaction of the obligation to help the poor is left to the conscience of the believer.

However, it is no less an obligation in virtue of being left to the believer. The law of a government does not necessarily reflect the content of a Muslim's moral obligations. Only insofar as a government's law incorporates the content of Sharia law does it express the content of the moral obligations defined by the Koran because Sharia law is directly derived from the Koran. Whether enforced by a state or not, every Muslim is obligated to help the poor and this obligation is part of Sharia law as expressed in Islamic Scripture. While there is much that the Abrahamic classically theistic faiths disagree upon, they are united in holding that helping the poor is a moral obligation.

Nor should it be thought that there is any requirement that the recipient have exhausted all efforts to create opportunities for himself. The Scriptures of all these religions were written at a time when resources were so scarce one simply could not manufacture appropriate economic opportunities. While we now live in a world in which one can do exactly that (provided one has adequate resources at least in the form of proper training), the concern

less than justice," Jewish Literacy, available at: http://www.aish.com/literacy/mitzvahs/Day to Da y Judaism Charity.asp. (Accessed February 22, 2007).

${ }^{7}$ For a helpful but brief discussion of the five pillars of Islam, see Malise Ruthven, Islam: A Very Short Introduction (Oxford: Oxford University Press, 1997), pp. 143-48. 
of these religious with the duty to alleviate poverty is not with such contingencies. ${ }^{8}$

\section{Peter Singer"s Drowning Infant Case}

Peter Singer asks us to consider the following situation. An adult notices an infant face down at the edge of a nearby pond in some very shallow water and can see the infant is flailing. Instead of simply bending over and removing the infant from the water, a gesture that would cost him no more than a few seconds and some wet hands, he walks by without doing anything and allows the infant to drown. People almost universally react to this case with a judgment that the adult has done something grievously wrong.

Most people view this situation as a counterexample to the view that we have no positive obligations to help others - even, in my experience, persons who initially hold this view. Indeed, I frequently present this case in applied ethics classes to students who nearly all begin this portion of the class with the view that all our obligations are negative; despite this, they almost universally respond quite passionately that a grave wrong has been committed. After realizing that their initial view is inconsistent with their reaction to this case, they overwhelmingly abandon their initial view that all our obligations are negative.

Singer infers from this example that we have an obligation to save the life of another person if we can do so without sacrificing something of comparable moral significance, but the example will not support such a strong principle. The reason is that the example involves a person who can save an infant at trivial cost to himself; it would be one thing if he had to risk injury to do so, but the example is couched so that the costs are minimal - temporarily wet hands and a few seconds of lost time.

At most, we can infer the weaker principle that we have an obligation to save the life of another person if we can do so without incurring a significant cost to ourselves, but this is strong enough to entail a robust obligation on the part of the affluent to alleviate the life-threatening conditions of absolute poverty. Sacrificing a $\$ 30$ shirt one does not need in order to save the life of a desperately malnourished child for one month is a trivial cost for someone who makes $\$ 40,000$ per year, about the aver-

\footnotetext{
${ }^{8}$ Another outstanding point I owe to Johannes Britz.
}

age income in the U.S. A national commitment of even $\$ 100$ billion per year to foreign aid is insignificant in an economy worth $\$ 12$ trillion dollars. Indeed, $\$ 100$ billion is about $3.5 \%$ of the $\$ 2.9$ trillion budget President Bush recently asked Congress to approve. In 2005, the U.S. spent about $\$ 28$ billion in foreign aid. ${ }^{9}$ Clearly, even the weaker principle that can be extracted from Singer's example entails that the U.S. is morally obligated to do much more.

\section{Alleviating Life-Threatening Effects of Bad Moral Luck}

It might be tempting to think that merit largely determines how material resources are distributed in the world. We are affluent and they are not, on this line of thinking, because we have earned it and they have not. While poverty is always regrettable, it does not necessarily involve justice: as long as people have gotten everything they deserve, there is no injustice in their having less than they need. We are our own keepers, and our respective merits determine what distributions are just. In other words, we have what we have because we have earned and hence deserve it.

While desert plays a role in explaining why people have what they have, luck plays as large a role. Had, for example, Bill Gates's parents lived in conditions of absolute poverty in a developing nation instead of an affluent suburb of Seattle, he would not be living anything like the kind of life he lives. He would surely not be the world's richest man or the head of Microsoft because he would not have had access to the resources available in an affluent nation like the U.S., including an education that made it possible for him to achieve the level of digital and business sophistication needed to start a successful corporation like Microsoft. Indeed, the probability that Gates would not also be mired in conditions of absolute poverty is so low as to be morally negligible. Although Gates's personal merits obviously played an important role in his success, luck played an equally important role: he lucked into being born into the affluent world instead of the developing world and that has made all the difference.

\footnotetext{
${ }^{9}$ Anup Shaw, "The U.S. and Foreign Aid Assistance," Global Issues (October 7, 2006); available at: http://www.globalissues.org/TradeRelated/Debt/U SAid.asp. Accessed February 17, 2007.
} 
The same is true of anyone who lives in the affluent developed world. Most of us who enjoy affluence in these nations have done something to deserve it, but we also owe what we have to not having had the misfortune of being born to parents living in conditions of life-threatening poverty who lack access to the basic resources affluent persons take for granted: adequate nutrition, water and shelter, as well as 12 years of free education and government funding available for a university education.

There is, of course, nothing morally wrong with being lucky. What we luck into is, by definition, beyond our control and not hence subject to moral evaluation. The idea that someone commits a moral wrong in virtue of having something happen to her utterly beyond her control is clearly absurd.

But whether we keep all we have lucked into is something within our control and subject to moral evaluation. Of course, it would be ridiculous to claim that it is always wrong to keep what we have lucked into; this would imply that we all should give up all of our material resources given that what all of us have depends so critically on the good fortune of having been born in an affluent country.

Sometimes it is just and hence morally permissible to keep all that you have lucked into on a particular occasion. If, for example, my neighbors and I contribute a modest amount to fund a lottery game we will all play, it seems reasonable to think that, other things being equal, there is no injustice with the winner's keeping the prize - even though the result of the game is determined by luck and no one can antecedently claim to deserve the winnings.

But substantive principles of justice link the justness of a holding to its being deserved. As a general matter, justice requires that people get what they deserve - whether we are talking about retributive, corrective, or distributional justice. Although the last paragraph suggests that it is not necessarily unjust to keep undeserved holdings, undeserved holdings are presumptively problematic in the sense that keeping them requires justification. In the context of retributive justice, for example, it is clear that giving a person more punishment than she deserves is unjust.

It is reasonable to think that the intrinsic worth of human life entails that every person deserves, at the very least, a fair opportunity to survive. Of course, if there is really not enough to go around, then some people will not survive, and this does not raise any issues of injustice as long as resources are as otherwise fairly distributed as is compatible with their being so scarce. In this world, people die and no one can be blamed on grounds of justice - even if some who survive owe their survival to luck; in this tragic world, it is not unjust to hold on to undeserved resources needed to survive.

But this is not the world in which we live; our world is a world where there is much more than enough to go around, yet some have billions of dollars and others lack consistent access to adequate food and water. Someone who has much more than needed to survive partly in virtue of luck denies to others a fair opportunity to survive. Keeping all those resources is keeping something she does not deserve, while denying to others something they do deserve - and this seems clearly unjust.

Here it is important to remember that it is the moral equivalent of a game of chance that determines where one is born. When a person cannot opt out of a game of chance and the results of that game largely determine whether she will have much more than she needs to survive or whether she will instead struggle mightily just to satisfy her basic needs (and sometimes fail to do this), those who have the good fortune to draw birth in the affluent world owe an obligation of justice to those who have the misfortune to draw birth in conditions of absolute and hence life-threatening poverty.

\section{Consequentialism and Deontological Moral Theories}

There are two main species of normative ethical theory that evaluate acts rather than character: consequentialism and deontology. Consequentialism is the view that the moral value of any action is entirely determined by its consequences in bringing about some objectively desirable state of affairs; for example, act utilitarianism holds that the first principle of ethics is the obligation to maximize "utility," which may be defined in terms of pleasure, wellbeing, happiness, or satisfied preferences. Strictly speaking, deontology can be accurately described as the negation of consequentialism: the moral value of at least one act is partly determined by features intrinsic to the act, rather than the consequences of the act. For example, an act utilitarian would have to explain the wrongness of lying in terms of features extrinsic to the lie (namely, the effects of the lie on total utility), whereas a deontologist can explain the wrongness in lying in terms of its inherent features (namely, its deceptive character). 
While there are different consequentialist theories and different deontologolical theories, a brief consideration of two of the most historically influential, I hope, will suffice to show these different theories generally converge on the view that we have a moral obligation to help the poor. This is not to say that every consequentialist and deontologlcal theory has this result; there may well be particular theories that hold that helping the poor is good but not required. But this, I hope will be evident, will be the exception and not the rule.

Consider, to begin, act utilitarianism's claim that our sole obligation is to maximize utility. Here it is important to note that material resources have diminishing marginal utility once basic needs are satisfied. Once basic needs are met, each successive increment of disposable income has less value to us than the last increment of the same amount. For example, a person making $\$ 45,000$ per year, other things being equal, will derive less utility from a $\$ 5,000$ raise than someone making $\$ 40,000$ per year. If this is correct, then utility will be maximized by moving it from people who have more than they need to people who have less than they need.

Indeed, it is for this reason that many act-utilitarian theorists believe we are obligated to distribute material resources so everyone has an equal share; if you have $\$ 50,000$ and I have $\$ 40,000$, the utility of an additional $\$ 5,000$ to me exceeds the utility of the $\$ 5,000$ you have over $\$ 45,000$. Accordingly, to satisfy your obligation to maximize utility, you should give me $\$ 5,000$, which would equalize our share of the resources.

The point here is not that all act utilitarians are egalitarian with respect to distributive justice; many would argue that, notwithstanding the diminishing marginal utility of non-necessities, an equal distribution of income would ultimately reduce community utility because it would remove an incentive to engage in productive activity that increases the community's material resources. The point, rather, is that egalitarians with respect to distribution of income are quite frequently act utilitarians who ground their position in the diminishing marginal utility of resources not needed to satisfy basic needs. One way or another, the diminishing marginal utility of non-basic material resources pretty clearly implies, on an act utilitarian view, an obligation to move disposable income to persons who lack the basic necessities.

Deontological theories almost universally hold that we have an obligation to help the poor. Consider, for example, Immanuel Kant's view that the first principle of ethics, the first categorical imperative, entails an obligation to help the poor. According to the first categorical imperative, we should act only on those maxims (i.e., principles that explain our acts) that we can consistently universalize (i.e., consistently will these maxims as universal laws everyone always acts upon). Here is what Kant has to say about its application to the issue of whether we have an obligation to help the poor:

A fourth, who is in prosperity, while he sees that others have to contend with great wretchedness and that he could help them, thinks: "What concern is it of mine? Let everyone be as happy as Heaven pleases, or as he can make himself; I will take nothing from him nor even envy him, only I do not wish to contribute anything to his welfare or to his assistance in distress!" Now no doubt if such a mode of thinking were a universal law, the human race might very well subsist and doubtless even better than in a state in which everyone talks of sympathy and good-will, or even takes care occasionally to put it into practice, but, on the other side, also cheats when he can, betrays the rights of men, or otherwise violates them. But although it is possible that a universal law of nature might exist in accordance with that maxim, it is impossible to will that such a principle should have the universal validity of a law of nature. For a will which resolved this would contradict itself, inasmuch as many cases might occur in which one would have need of the love and sympathy of others, and in which, by such a law of nature, sprung from his own will, he would deprive himself of all hope of the aid he desires. ${ }^{10}$

Of course, many theorists worry that the first categorical imperative, applied as Kant intends, will not have many of the substantive results that Kant believes it has; the first categorical imperative seems to work only on acts that involve some sort of deception. But the point is that Kant himself believed that we have a moral obligation to help the poor, and he believed this was a transparent application (after all, he devotes only one paragraph to the argument) of the first categorical imperative.

${ }^{10}$ Immanuel Kant, Fundamental Principles of the Metaphysic of Morals, Second Section; available at http://etext.library.adelaide.edu.au/k/kant/imman uel/k16prm/prm3.html. 
Another influential deontological theorist, W.D. Ross, took the position that we have a number of prima facie duties that, taken together, determine what we are obligated to do on any given occasion. As Ross describes it, "'Prima facie duty' is a brief way of referring to the characteristic (quite distinct from that of being a duty proper) which an act has, in virtue of being of a certain kind (e.g., the keeping of a promise), of being an act which would be a duty proper if it were not at the same time of another kind which is morally significant" (377). A duty is a prima facie duty in the sense that it is presumptive and can be overridden by a stronger prima facie duty; what we are ultimately obligated to do is determined by the strongest of these presumptive duties.

Ross gives what he takes to be a complete list of prima facie duties: (1) Those resting (1) on a promise; (2) on a previous wrongful act; (3) on previous acts of other persons (e.g., services that may give rise to a duty of gratitude); (4) on a distribution of pleasure or happiness; (5) on persons whose conditions we can make better (duties of beneficence); (6) on the ability to improve our own conditions (duties of self-improvement); (7) on the harmfulness of certain behaviors on others (duties not to harm others). Proposition (5), of course, describes a prima facie obligation to help the poor.

Notoriously, Ross does not provide any theoretical considerations that would enable us to determine what is, all things considered, our proper (or ultimate) duty; however, this is not really relevant for our purposes. Certainly, the obligation to help the poor is not absolute in the sense that it takes precedent over all other duties. It seems clear that a person of limited means has a duty to take care of her family that outweighs the duty to help the poor if she cannot do both. The point of this section is simply to suggest that, whatever else they might disagree upon, consequentialist and deontological theories typically (though not necessarily) agree that the affluent have a moral obligation to help the absolutely poor.

\section{What Would Have to Be Done to Solve These Problems?}

So if we assume, as I am willing to do, that these divides are problems of justice that require a solution, the question is how do we go about solving them? This much is clear: the solutions will be expensive and much more complicated than can be addressed in a few short pages. Accordingly, I purport to do no more than provide a brief sketch of some the obstacles to bridging the divide and the poverty it perpetuates.

At the outset, it is worth noting that the affluent world cannot provide all of the benefits associated with meaningful access (construed to include some threshold level of skill in using them) to ICTs simply by providing the relevant ICTs and training to impoverished nations.

There are a number of problems here. First, and most obviously, you cannot eat ICTs, Internet access, or information; if we are dealing with countries with life-threatening poverty (and much poverty in the developing world is absolute in this sense), then the very first step in providing meaningful access to ICTs is to ensure that these more basic needs are met. Someone who is malnourished and sick will not be in a position to take advantage of ICTs no matter what else is done. So part of the program will have to include provision of foodstuffs, clean water, and healthcare to free people from having to devote all their time and energy just to ensure their bellies are full enough to keep from keeling over - something that affluent nations have done much too little to address up to now.

Second, other kinds of physical infrastructure are needed in developing nations to ensure that people have access to the opportunity to participate in the online economy. As Johannes Britz observes, the affluent have no problem ordering goods from Amazon.com because they have homes with road access making it possible for UPS or Fed-Ex to deliver those goods. In many places in Africa, especially Ethiopia, people live away from roadways and must walk long distances to school and work, but this situation also prevents UPS and Fed-Ex from delivering goods there. ${ }^{11}$ Indeed, one must have a credit card to make such purchases - and impoverished people in the developing world do not have credit cards.

Third, and most importantly, people must not only have the relevant ICTs, but also the ability to utilize these ICTs to produce output that is ultimately marketable in a global economy. People once thought that having access to radio technology would improve the economic lot of poor persons in the developing world; evidence now suggests there are more radios in South Africa than mattresses, but

${ }^{11}$ I owe this important point to Johannes Britz. 
unemployment is high at more than $30 \%$ and disproportionately affects blacks. Similarly, Internet access does no good in alleviating poverty if all that is done with it is to download the latest product from Hollywood for the purpose of amusing oneself.

What is needed is a particular type of skills - the type that enables a person to use ICTs and information to produce output that is in demand. Only where impoverished persons are in a position to produce something other people want to buy can they raise their standards of living. Obviously, these skills include programming, designing websites, and so on; less obviously, they require at this point in time training in English, which is increasingly becoming the world's language of commerce - although it would clearly be ideal to make efforts to ensure the easy availability of devices that accurately translate the contents of a website in one language into any other of the world's written languages. Sadly, at this point in time, the developing world lacks the resources to provide such training.

But even adequate training isn't enough. To improve the lot of poor countries, affluent countries must provide fair, competitive opportunities for a person to take advantage of her skills. While more and more people are getting such opportunities through corporate outsourcing, they do not receive a fair wage - though what they receive is more than what they could otherwise earn.

The benefits of these new opportunities are often offset through laws that protect the interests of affluent developed nations at the expense of developing nations. The most conspicuous example here is the law of intellectual property, and especially the protection of intellectual property rights in software. To compete in a global economy in which information is an increasingly valuable marketable commodity, people need meaningful access to the software that makes utilization of ICTs so productive in the affluent world. But current intellectual property laws have the effect of allowing corporations to maintain pricing levels that effectively bar legal access to these products among people in the developing world. If Nike's outsourcing menial work (at exploitative wages) improves the standard of living of employees in the developing world, it does not raise that standard enough to enable those persons in the developing world to acquire the software and skills to lift themselves out of a condition where they must perform menial and uninteresting labor to survive.
Corporations can, and should, do something to change this unfortunate state of affairs. Corporations surely have a morally legitimate interest in the content they create and make possible and surely deserve a fair rate of return for that product. But when it comes to products that are needed to alleviate absolute poverty, which include not only software but also medicine for the diseases that are endemic in the Global South, they should, as a moral matter, waive these rights so as to make these products genuinely available in the developing world.

Moreover, corporations should ensure that jobs outsourced to absolutely poor nations be paid a fair wage. Too often, the wages paid to people in absolute poverty are far less than what would be paid an employee in a Western nation. Although it is true workers in the developing world make more from outsourced work than they otherwise would and thereby benefit economically, it is also true the wages are so much less than the work would merit in the nations from which it is outsourced that it borders on exploitation. Corporations should contract on fair terms; the economic benefits alone are not a justification for exploiting persons. ${ }^{12}$

The economic benefits made possible by corporate outsourcing of work to the developing world are also offset by unfair conditions attached to foreign aid. Sadly, the World Bank and IMF (and even the US agency responsible for providing foreign aid) frequently tie the provision of aid to the satisfaction of conditions that make matters worse because they ignore a culture's history, mores, social conventions, and ways of organizing economic activity. The most frequent condition is to insist that recipient countries immediately carry out system-wide political and economic reforms - which typically make things worse, in part, because affluent nations demand full access to all emerging markets in developing nations while protecting vulnerable markets (like agriculture) in affluent nations where costs of labor are much higher. The effect is that emerging industries in developing nations are destroyed along with what few jobs there might be to support the population. In some instances, it seems reasonable to think that these nations would be better off without such conditional aid, but the conditions of absolute poverty make it difficult to turn it down.

\footnotetext{
12 I am indebted to Johannes Britz for yet another insightful point here.
} 
This is a complicated issue that cannot be done justice here but there are two conspicuous examples illustrating the folly of one economic and political culture trying to impose an image of itself on another. Shortly after the Berlin Wall fell, the IMF was charged with the responsibility of overseeing a process in which Russia went from a centrally organized economy run by the state to a fully privatized system of free enterprise. The result has, thus far, been a disaster. Many people are far worse off in both economic and security terms: Russia is poorer and more dangerous than it ever was under Soviet-style socialism. Indeed, the complaint is not infrequently heard among Russians that the country was better off as a socialist totalitarian state.

This is, of course, not to say that Soviet-style socialism was good. It is rather to point out the folly of efforts by market fundamentalists, such as those who have disproportionate influence in the IMF, to foist total privatization on countries whose history and culture affords no reason for thinking such a transition could be anything other than an unmitigated disaster.

Unfortunately, these problems are consistently lost on decision-makers in the IMF who continue, along with the World Bank, to tie loans and other forms of aid to developing nations to economic conditions that are all but certain to exacerbate, rather than alleviate, absolute poverty and the accompanying divides in both ICTs and information. One would have hoped the obvious fact that the problems caused in Russia would reduce the temptation to try to remake every developing nation in our image without sufficient knowledge of the history, culture, and traditions of the affected nations.

In contrast, China is one of the economic success stories of the twentieth century. The process of privatization in China has been gradual, having begun almost accidentally with the discovery among farmers tending a collectivized farm that allowing people to take control over particular sub-parcels and keep the profits resulting from their efforts dramatically increased production figures and net wealth. In response, China sanctioned the privatization of farming and enjoyed spectacular results - all the while protecting vulnerable industries that were unable to compete favorably with corresponding Western industries, a practice that was quite common in Western industrialized nations.

Indeed, it is particularly worth noting that the spectacular growth of the U.S. economy prior to the formation of the WTO depended in large measure on economic barriers on trade designed to protect vulnerable developing industries. These barriers included such devices as tariffs and special taxes on goods imported to the U.S. from other countries, as well as legal restrictions on imported goods - a practice the WTO continues on a more limited basis even while insisting, as a condition of aid, that developing nations completely open their markets to foreign competition.

The result of the controlled privatization of Chinese economic activity is that no country has had more success in moving from state socialism to free enterprise. While the gap between rich and poor has, of course, widened, China has taken steps to ensure that the very poorest have also benefited. In consequence, it is reasonable to think that (1) China will be a democracy in 50 years and (2) China will be the world's largest economy and the U.S.'s fiercest rival in the competitive world market at that time. The contrast between the failure of instant privatization in Russia and the success of gradual, controlled privatization in China, as well as the reasons for this contrast, could not be clearer.

Yet the IMF, World Bank, and USAID continue to condition loans and other financial aid to developing nations on policies that have ruined Russia's economy and would have ruined the United States' own economy had those policies been imposed upon us. It is tragic that these mistakes continue to be made when they could be so easily avoided with some cultural sensitivity.

Compounding the problems of these poor nations, of course, is the staggering debt they owe to representatives of affluent nations like the IMF and the World Bank. A few statistics suffice to convey the desperate character of the situation. African nations annually pay about $\$ 15$ billion in debt service on an outstanding debt of $\$ 230$ billion. That is $\$ 1.30$ in debt service for every $\$ 1.00$ in foreign aid.

If these numbers seem, at first blush, significant from the perspective of an affluent nation, one need only consider that George Bush recently asked Congress for a federal budget in 2008 of $\$ 2.9$ trillion dollars. $\$ 230$ billion dollars is chump change indeed, less than $10 \%$ - compared to the size of the U.S. budget; and it is less than $2 \%$ of the value of the U.S. economy last year: in 2006, the GDP in the U.S. was approximately $\$ 13$ trillion. If citizens of the U.S. were to bear the cost of forgiving the debt, it would amount to a tax increase of no more than $\$ 80$ per citizen per year for ten years (significantly less than the price of designer jeans). If citizens of 
affluent European nations were to do their share in bearing the cost of forgiving the debt, it would reduce the cost per citizen to $\$ 31$ per year (about the price of a movie and popcorn for two people) for ten years.

Although these figures are trivial for nations as rich as the U.S. and European nations, they greatly inhibit the ability of African nations to address all the important problems of absolute poverty. African nations spend about $1 / 4$ of the cost of debt service per year on healthcare. In some nations, healthcare spending is $\$ 7$ per year per person - a fraction of what is needed to deal with the HIV pandemic in Africa. Education expenditures in Africa have decreased dramatically, forcing schools to close or charge exorbitant fees. The result is a workforce that is less knowledgeable, less skilled, and more likely to be left further behind in an increasingly competitive global economy.

No comparatively short discussion of the problems faced by absolutely poor nations in the developing world can possibly be sufficient to convey the full spectrum of problems faced by the developing world, but it is enough that a number of conclusions can plausibly be drawn. This much is clear: the solution to the information and digital gaps between the developed and developing world will have to involve a multifaceted approach that includes, at the very least, the following elements: (1) unconditional cancellation of all debts owed to the IMF and World Bank unless there is compelling reason to think that the relevant regime is so corrupt that debt cancellation will not result in improvement in the condition of the poor; (2) increasing unconditional aid to the developing world that is targeted to provide food, healthcare, and infrastructure that will produce meaningful opportunities for citizens to improve their lives in the information society; (3) unconditional aid directed at providing education necessary for persons to use ICTs and information to their economic benefit; and (4) a commitment to provide all such unconditional aid, until at the very least, two conditions are satisfied. First, the lifethreatening effects of absolute poverty have been permanently eradicated; and, second, the population has access to ICTs and possesses all the intangible (e.g., knowledge) and tangible (e.g., roads and other infrastructure) resources to significantly benefit from information-related market transactions among nations in the global economy.

While there are doubtless other conditions that must be fulfilled and hence that those enumerated above are not sufficient to eradicate absolute poverty, they are surely necessary. No collective or individual effort that fails with respect to one of these particulars can hope to make real progress in efforts to provide the poorest nations with access to the information economy that will enable them to achieve significant economic progress in addressing their worst problems. 